\title{
A participação do assistente social na judicialização dos conflitos sociais
}

Marcos Francisco de Souza*

Resumo: Este artigo tem como objetivo apresentar algumas reflexões sobre a participação do assistente social na judicialização dos conflitos sociais, trazendo subsídios para problematizar, numa perspectiva de totalidade, a imediaticidade das requisições sociais, políticas e ideológicas do Poder Judiciário brasileiro e as mediações e contradições do trabalho do assistente social, enquanto parte constitutiva e constituinte dos conflitos judicializados.

Palavras-chave: trabalho, Poder Judiciário, assistente social.

The participation of the social worker in the judicialization of the social conflicts

Abstract: This paper presents some reflections upon the participation of the social worker in the judicialization of the social conflicts, bringing contribution to analyze, from the perspective of totality, the immediacy of the social, political and ideological solicitations of the Brazilian Judiciary system and the mediation and contradictions of the work of the social worker as the constituent part of the judicial conflicts.

Keywords: work, Judiciary system, social worker.

Mestre em Política Social pela Universidade de Brasília (Unb). E-mail: marcosfsoueu @ yahoo.com.br 


\section{Introdução}

O Judiciário vem se constituindo num dos principais espaços ocupacionais do assistente social não só pela condição legítima de "árbitro" na resolução dos interesses conflitantes na sociedade, mas pelo compromisso político com a consolidação do Estado democrático de direito brasileiro. Por outro lado, esse compromisso político tem se confrontado, em determinadas instâncias e conjunturas, com o caráter regulador e controlador característico desse Poder, gerando desafios teóricos, técnicos e éticos para o assistente social que participa, na condição de assessor, da resolução dos conflitos judicializados. ${ }^{1}$ Tais desafios estimulam a busca por respostas e permitem problematizar e polemizar as contradições e mediações que particularizam o ser e o fazer do assistente social na esfera judiciária. ${ }^{2}$

\section{A judicialização dos conflitos sociais}

Ao definirmos como ponto de reflexão a judicialização dos conflitos de natureza social, partimos para uma escolha teóricometodológica marxista, pautada na ontologia do ser social, para explicar a base constitutiva das relações sociais, ${ }^{3}$ ao

1 Entendemos como conflito judicializado todo o processo por meio do qual um cidadão em conflito ou dissídio com outro, com um grupo, uma entidade ou o próprio Estado procura uma instituição judiciária com o intuito de submeter à sua vontade a de outrem.

2 As reflexões aqui apresentadas são produto de uma pesquisa sobre as determinações e particularidades do trabalho do assistente social nos órgãos do poder judiciário sediados em Brasília, e pré-requisito para a obtenção do título de Mestre em Política Social na Universidade de Brasília (UnB).

3 Ao discutir os princípios da sociabilidade humana, Marx (1980) assinala, nos manuscritos de A ideologia alemã, que a condição fundamental de toda história é a capacidade que o homem tem de produzir, por meio do trabalho, os meios que permitam a satisfação de suas necessidades. Isto é, para Marx, o homem deixar de ser um homem animal para ser um homem social a partir do momento em que transforma elementos da natureza para satisfazer necessidades. 
mesmo tempo em que nos afastamos das visões estritamente biologizantes, psicologizantes e jurídicas dos conflitos. Assim, partimos da visão marxista de que a contradição (e o conflito como sua expressão imediata) é algo constitutivo do ser social em sua totalidade e complexidade. Este ser social produz e reproduz relações sociais que, historicamente, adquirem formas e conteúdos complexos e heterogêneos ou, como assinala Yasbeck (1999, p. 87), "a reprodução de determinado modo de vida, do cotidiano, de valores, de práticas econômicas, políticas e culturais e do modo como se produzem [reproduzem] as idéias". Logo, não há como pensar qualquer conflito que não seja, antes de tudo, social. Ao contrário, como produto das relações entre indivíduos, entre indivíduos e grupos, entre grupos e entre indivíduos, grupos e instituições, os conflitos são o motor de todo e qualquer processo de mudança, em diferentes e diversificados níveis.

Nesse sentido, nos solidarizamos com a concepção sóciohistórica que vê a sociedade como produtora e reprodutora de conflitos sociais de natureza e formas diferenciadas. Por outro lado, essa mesma sociedade produz e reproduz formas institucionalizadas ou não de resolução desses conflitos, sob a justificativa da garantia de "coesão social" - concepção, aliás, apropriada historicamente por algumas sociedades para impor medidas coercitivas ou mesmo persuasivas a indivíduos, grupos e instituições que, de certa forma, ameaçavam (ou ainda ameaçam) essa "coesão". Essa foi (e continua sendo em determinados contextos) a base justificadora dos chamados contratualistas (Hobbes, Locke e Rosseau) para legitimar a necessidade da criação, no seio da sociedade, de um terceiro agente - o Estado -, como disciplinador, regulador e controlador do comportamento dos indivíduos. Aliás, essa base justificadora está fortemente presente na concepção do Direito brasileiro, assim como no Judiciário, enquanto forma 
institucionalizada das idéias de Direito e de Justiça. Ou seja, do ponto de vista jurídico brasileiro, a resolução do conflito pressupõe a garantia da regulação e do controle social. ${ }^{4}$

Da mesma forma que os conflitos sociais produzidos e reproduzidos são de natureza e formas múltiplas, heterogêneas e diferenciadas, os mecanismos de resolução também o são. Ou seja, a resolução pode se dar: por vias institucionais ou não institucionais; seguir critérios legais pré-existentes ou somente o "senso de justiça"; seguir as formas coercitiva, persuasiva ou negociada (baseada em princípios democráticos e pelo reconhecimento do outro como cidadão).

\section{A organização socioinstitucional do judiciário}

O Judiciário brasileiro tem se constituído como um dos caminhos para a resolução dos conflitos oriundos das ações, interações e relações sociais produzidas no modelo de organização econômica, política, social e cultural da sociedade brasileira. No entanto, não podemos desconsiderar que, na sua função de administrar a resolução dos conflitos, o Poder Judiciário precisa ser requisitado para tal, ${ }^{5}$ de forma que o seu poder de decisão está condicionado à formalização desses conflitos por meio dos outros mecanismos institucionais do Estado e da sociedade, como: as polícias judiciária, civil e militar, as promotorias, defensorias públicas e organizações

4 Definimos como controle social o conjunto de regras, valores, costumes, símbolos compartilhados por indivíduos, grupos e instituições para mantê-los em conformidade com os padrões de comportamento aceitos (Torre, 1971). Partimos desta visão positivista por entendermos que ela ainda constitui, predominantemente, a base teórica e filosófica do Direito brasileiro.

5 O direito do indivíduo em ter seu conflito resolvido está baseado na idéia do direito subjetivo, entendido como a faculdade atribuída à vontade de alguém solicitar tutela jurisdicional, a fim de que se realize a subordinação do interesse de outrem ao seu (Lisboa, 1999). Daí, o poder judiciário ter assumido historicamente uma postura reativa, ou seja, ele precisa ser acionado ou provocado. 
não-governamentais que objetivam a garantia de direitos de grupos e segmentos sociais específicos. Por outro lado, o Judiciário brasileiro tem experimentado nos últimos anos, mesmo que embrionariamente, formas alternativas de resolução dos conflitos, numa perspectiva pró-ativa identificando e administrando os conflitos antes que eles se judicializem, ou seja, antes que caiam nas armadilhas da burocratização e do excesso de formalismo característicos desse Poder. ${ }^{6}$

Para além do processo de democratização, que tem permitido à sociedade brasileira o controle da coisa pública (no sentido estatal) e o reconhecimento legal de novas e tradicionais formas de resolução de conflitos, parece haver no imaginário social o entendimento de que a exacerbação dos conflitos gerados no ambiente privado, comunitário e institucional só adquire uma dimensão legítima quando administrado pelo Estado, por meio do Judiciário, enquanto expressão materializada (diríamos idealizada) dos ideais de justiça, eqüidade e democracia, enfim, enquanto medida de justiça (Telles, 2001).

Ao tomar para si a administração dos conflitos judicializados, o que, em última instância, implica a extinção do processo judicial, o Judiciário (representado na figura do magistrado) depara-se com questões de natureza psicológica e social (equivocadamente designadas de "parajurídicas") que, na sua maioria, são parte constituinte e constitutiva do próprio conflito judicializado e que podem interferir (ou estão interferindo) na resolução do conflito. Essa prerrogativa parece

6 Dentre as formas alternativas de resolução de conflitos podemos citar os projetos experimentais do Tribunal de Justiça do Distrito Federal e Territórios como os de Justiça Comunitária e Justiça Restaurativa. Vale ressaltar que essas iniciativas representam, em certa medida, uma resposta do Poder Judiciário às críticas daqueles estudiosos que apontam a sua ineficiência e ineficácia para garantir indistintamente o acesso universal dos cidadãos à justiça. Ver Castro (1998) e Faria (1996). 
expressar a base sócio-histórica ${ }^{7}$ de inserção de profissionais de outras áreas do conhecimento humano-social (inclusive - e principalmente - de assistentes sociais) para assessorar as decisões dos magistrados no que diz respeito ao julgamento, execução, acompanhamento e extinção da "medida judicial" imposta aos sujeitos em conflito com a lei.

\section{A inserção do assistente social na divisão sociotécnica do trabalho no judiciário}

O assessoramento do assistente social na administração dos conflitos judicializados apresenta-se, a priori, numa função aparentemente imediata de subsidiar as decisões judiciais. No entanto, o grau de abrangência desse assessoramento determina-se pela natureza dos conflitos, pelo nível de atuação da circunscrição judiciária ao qual o assistente social está subordinado, às estratégias e táticas de intervenção e produção de conhecimento profissional, à busca da construção da identidade e do reconhecimento profissional em nível institucional, ao projeto ético-profissional do assistente social.

Primeiro, porque, por motivos que os limites deste artigo não permitem abordar, não são todos os conflitos sociais que se tornam objeto de intervenção do poder judiciário.

Segundo, porque o fluxo de judicialização desses conflitos possui um caráter contingencial, pois está condicionado a conjunturas externas à própria instituição, por exemplo, ao aumento de:

\footnotetext{
Podemos dizer que qualquer esforço de apreender as condições sócio-históricas de inserção do assistente social no judiciário dever ser seguido da constatação de que esta inserção foi o resultado, de um lado, do próprio movimento de expansão e complexificação das funções sociais, políticas e institucionais da justiça brasileira, e, do outro, do próprio movimento de construção de táticas e estratégias de legitimação e reconhecimento da profissionalidade do Serviço Social na estrutura de organização e funcionamento do Poder Judiciário. Ver Souza (2004).
} 
- casais que procuram a vara de família para formalizar a separação de corpos;

- denúncias de casos de exploração, negligência, violência e abusos físicos e sexuais de crianças e adolescentes;

- casais interessados em regularizar ou se habilitar à adoção;

- familiares que solicitam a interdição civil de um de seus membros;

- adultos que cometem crime contra a pessoa ou patrimônio público ou privado;

- usuários e traficantes de drogas; e,

- portadores de transtorno mental que cometeram delitos de natureza criminal.

Terceiro, porque a identidade profissional do assistente social está "diluída" na identidade de profissionais de outras áreas do conhecimento humano-social, como a Psicologia e Pedagogia, o que torna o espaço de trabalho do assistente social permeado por interesses e concepções teóricometodológicas, técnico-operativas e ético-políticas diferentes e divergentes.

A postura predominantemente reativa atribuída ao Judiciário está pautada na divisão entre o direito objetivo e o direito subjetivo. O primeiro constitui-se num sistema de normas gerais e abstratas criadas pelo Estado para administrar os interesses conflitantes da sociedade, ao passo que o segundo tem origem na vontade de alguém solicitar a tutela jurisdicional, a fim de subordinar os interesses de outrem à sua vontade (Lisboa, 1999).

O sistema de normas gerais e abstratas (expressas em leis, regimentos e decretos) determina como será o processo 
de formalização, isto é, de institucionalização dos interesses conflitantes da e na sociedade, o que significa dizer como será a divisão jurídico-legal e a divisão socioinstitucional dos conflitos judicializados.

A divisão jurídico-legal contempla a judicialização dos conflitos de natureza constitucional, criminal, civil e infracional (para os casos previstos no Estatuto da Criança e do Adolescente). O TJDFT possui como área de competência jurisdicional apenas os conflitos de natureza civil, criminal e infracional, os quais se constituem em objeto privilegiado (mas não exclusivo) do conhecimento e intervenção dos magistrados, além de se tornarem, muitas vezes, o único referencial definidor da "clientela da justiça" (o casal em litígio, o criminoso, o traficante, o estelionatário, o abusador, o louco infrator, o adolescente infrator, o adotante, o adotado etc.) e, de forma muitas vezes equivocada e acrítica, "clientela" do próprio assistente social.

Na verdade, o que se define como "clientela da justiça" está, muitas vezes, materializada, personificada e reduzida à figura jurídica que originou o processo de institucionalização do conflito e de tutela dos sujeitos judicializados, e, com isso, corre-se o risco de fragmentar, individualizar e particularizar demandas (entendidas como expressões da Questão Social ${ }^{8}$ ) da clientela que, na verdade, possuem condicionantes conjunturais e estruturais na esfera da vida social.

De igual modo, essa divisão jurídico-legal determina não apenas a inserção do assistente social na divisão do trabalho da instituição, mas permite também:

1) contextualizar os preceitos jurídico-legais que condicionam (e são condicionados) pelo trabalho

8 Entendemos como expressões da Questão Social, numa perspectiva marxista, o produto das desigualdades sociais oriundas do processo contraditório da apropriação da riqueza produzida socialmente por um grupo determinado. (cf. Iamamoto, 2001). 
do assistente social no âmbito das varas de família, da infância e juventude, varas criminais, vara de execuções criminais, vara de entorpecentes e contravenções penais e juizados especiais criminais da justiça do Distrito Federal;

2) revelar as particularidades assumidas pelo trabalho do assistente social no que diz respeito à natureza e à via de chegada das demandas institucionais e profissionais, aos meios e instrumentos utilizados para problematizar e intervir nas expressões da questão social e nos resultados do seu trabalho;

3) delimitar os usuários dos seus serviços.

A divisão socioinstitucional ${ }^{9}$ contempla todas as instâncias institucionais e organizacionais que garantem, tecnicamente, a administração dos conflitos, e, traduzida na prestação de serviços forenses, significa, grosso modo, o processamento, julgamento, execução, acompanhamento e extinção de "processos judiciais".

Ao exercer a sua função juridicante no âmbito da justiça do Distrito Federal (organizada em varas, juizados, turmas e câmaras civis, criminais e infracionais), o magistrado dispõe de um corpo de profissionais de diferentes áreas e níveis (onde se inclui o assistente social), com conhecimentos técnicos específicos para "auxiliá-lo", "subsidiá-lo" e/ou "assessorá-lo" e, assim, garantir o seu monopólio na resolução dos conflitos

9 Dentro da divisão sociotécnica do trabalho do TJDFT, a utilização dos conhecimentos técnicos do assistente social e se constitui, regimentalmente, num assessoramento de natureza psicossocial que determina a natureza institucional do trabalho desse profissional. Da mesma forma, o assistente social está inserido na primeira instância da justiça do Distrito Federal, responsável pelo julgamento, processamento, execução, acompanhamento e extinção de processos judiciais nas áreas de família, infância e adolescência, e criminal. 
sociais e, conseqüentemente, legitimação do papel mediador e civilizador do Estado brasileiro.

\section{As particularidades do assessoramento do assistente social}

O assistente social, juntamente com profissionais de outras áreas do conhecimento humano-social, como a Psicologia, a Pedagogia e a Sociologia, guarda a peculiaridade de participar diretamente da resolução do conflito, principalmente por dispor supostamente de uma pretensa capacidade de "extrair" dos seus estudos sociais uma "verdade" dos fatos não apreendida (ou apreendida superficial e equivocadamente) pelo saber técnicojurídico dos magistrados, ou mesmo uma certa previsibilidade sobre o comportamento dos sujeitos judicializados, ou melhor, dos sujeitos em conflito com a lei.

A busca da "verdade jurídica dos fatos" (no seu caráter absoluto) subordina-se, em certa medida, às verdades parajurídicas dos fatos (no seu caráter relativo, dinâmico e histórico) apreendidas no processo de estudo, problematização, análise e avaliação das expressões da Questão Social que podem interferir (ou estão interferindo) na resolução dos conflitos judicializados no âmbito da primeira instância.

Os trâmites processuais, característicos da administração da justiça brasileira, primam pela objetividade, veracidade e fidedignidade das informações que compõem os autos, de forma que, ao final do processo judicial, seja possível chegar a um "veredicto" (verdade dos fatos). No entanto, ao se falar em "verdade" na esfera das profissões que compõem as ciências sociais e humanas, o conhecimento adquirido acerca da trajetória de vida pessoal e social dos usuários da justiça está inerentemente circunscrito a uma realidade essencialmente humano-social - portanto, não pode ser apreendida dentro dos critérios de objetividade e neutralidade que caracterizam 
o direito positivista brasileiro, o que implica, do ponto de vista do trabalho do assistente social, não trabalhar com verdades absolutas, estáticas e a-históricas.

Ao contrário, todo o processo interventivo que caracteriza o trabalho do assistente social está voltado para a busca da realidade humana e social dos seus usuários, que é essencialmente dinâmica, complexa, heterogênea e multifacetada. Logo, os estudos realizados pelo assistente social procuram emitir um "parecer" (no sentido literal da palavra) sobre as condições pessoais, sociais e familiares dos seus usuários, por entendermos que, ao longo da sua trajetória de vida social, o usuário pode "ressignificar" e "redimensionar" a dinâmica das suas relações sociais, adquirindo novos referenciais e identidades sociais.

Devido à ampliação e complexificação das demandas judiciais, a condição de "subsidiários" das decisões judiciais possibilitou que os assistentes sociais também ampliassem o seu assessoramento na administração dos conflitos judicializados, atuando no julgamento, execução, acompanhamento e/ou extinção da "medida" judicial "imposta" pelo magistrado. Por exemplo, os conflitos oriundos dos pedidos de guarda e regulamentação de visitas por casais em separação litigiosa nas varas de famílias, dos pedidos de interdição judicial nas varas civis, e dos conflitos oriundos da violação dos direitos da criança e do adolescente no âmbito da vara da infância e adolescente exigem do assistente social o uso de conhecimentos teóricometodológicos, técnico-operativos e ético-políticos para assessorar o magistrado na imposição de "medida" judicial às partes envolvidas no conflito. Assim também, os conflitos oriundos de delitos de baixo, médio e alto poder ofensivo no âmbito da vara de execuções criminais e da vara da infância e da juventude (no caso de delitos cometidos por adolescentes em conflito com a lei) exigem do assistente social o uso 
de conhecimento técnico para assessorar o magistrado no acompanhamento, na fiscalização e na extinção da "medida" judicial imposta ao sujeito em conflito com a lei. E, ainda, os conflitos oriundos de relações violentas de gênero e de uso de drogas ilícitas no âmbito dos juizados especiais criminais exigem do assistente social o uso do mesmo conhecimento para exercer a função de execução da própria "medida judicial" "sugerida" (de forma persuasiva) pelo magistrado.

A postura predominantemente reativa do Poder Judiciário brasileiro- para além de um sistema de normas gerais e abstratas -, em geral, exige do cidadão uma "vontade" (nem sempre voluntária e espontânea) para que, ao acionar esse Poder, possa exercer o seu direito subjetivo que, para nós, seria a sua "medida de justiça". Essa "vontade" pode ser mediada por outras instâncias institucionais do Estado ou da própria sociedade como ocorre principalmente nos conflitos de natureza criminal e infracional, onde o sujeito agredido (digase, também, aquela instituição que teve seus direitos violados) delega ao Estado (representado na figura do Judiciário) o direito de impor uma "sanção" àquele que o "agrediu".

No TJDFT, as varas criminais, de execução penal, a Central de Penas e Medidas Alternativas, os juizados criminais e a Vara da Infância e Juventude (nos casos de infrações cometidas por adolescentes em conflito com a lei) exercem essa função e se tornam, por excelência, um lócus privilegiado de imposição, fiscalização e policiamento. Sendo assim, os sujeitos em conflito (criminal) com a lei são, geralmente, intimados compulsoriamente a comparecer perante o magistrado para tomarem conhecimento da formalização do conflito e, assim, as fases do processo prosseguem com 0 julgamento, a execução, a fiscalização, o acompanhamento e/ou a extinção da "sanção judicial". 
Por outro lado, a "vontade" de buscar a resolução dos seus conflitos pela via judiciária pode ser direta e, geralmente, ocorre nos conflitos de natureza civil que, no caso do TJDFT, referem-se ao direito de família (principalmente, quanto à definição da guarda dos filhos, na maioria das vezes, nas separações litigiosas, e à pensão alimentícia) e aos direitos da criança e adolescente (guarda, tutela, destituição do poder familiar, emancipação e adoção).

Os conflitos que envolvem os direitos da criança e do adolescente guardam a peculiaridade de poderem ser de natureza civil (via direta) ou criminal (via mediada), pois tanto o próprio "agredido" quanto as instituições defensoras e fiscalizadoras desses direitos e, ainda, outros agentes sociais (vizinhos, parentes, amigos etc.) podem delegar ao judiciário o poder de impor uma "sanção" àquele que violou os direitos da criança e do adolescente, assim como ao próprio adolescente que cometeu um ato infracional.

No TJDFT, ao exercerem essa função, as varas de família e da infância e juventude tornam-se, da mesma forma que nos conflitos de natureza criminal, lócus privilegiado de averiguação, policiamento e imposição, com a diferença de que, a vara da infância e juventude exerce tanto a função de averiguação, policiamento e imposição de sanções quanto de execução e acompanhamento dessas sanções.

O lócus privilegiado de imposição, fiscalização e policiamento jurídico torna-se, assim, um lócus privilegiado de atuação do assistente social, sobremaneira no que diz respeito aos desafios e às potencialidades de se exercer uma escuta profissional para além da esfera reguladora e controladora e, principalmente, para garantir o seu compromisso éticoprofissional com a perspectiva de consolidação e ampliação de direitos dos seus usuários. A função reguladora e controladora 
da judicialização dos conflitos somente é cessada quando a "medida judicial" é devidamente cumprida, significando, do ponto de vista institucional, a extinção da medida judicial.

Sob o prisma de auxiliar da justiça, na relação entre o poder institucional (jurídico-legal) e o saber profissional (técnico-profissional), o trabalho do assistente social está condicionado, na maioria das vezes, à determinação judicial, ou seja, naqueles casos em que os recursos técnico-jurídicos e jurídico-legais não são suficientes para garantir a resolução do conflito, tanto no que se refere à imposição da "medida judicial" quanto à sua execução, cumprimento e extinção. Com isso, pode-se dizer que a natureza e a via de chegada dos conflitos judicializados ao TJDFT determinam o tipo de demandas - espontâneas ou impostas - com as quais o assistente social se envolve profissionalmente.

As demandas espontâneas são aquelas que dependem da vontade "livre e consciente" de cidadãos e de entidades sociais que procuram orientações sobre procedimentos legais para pleitear ou regularizar adoções, formalizar pedidos de guarda, tutela, curatela, regulamentação de visitas e emancipação. Essas demandas espontâneas podem gerar outras orientações e encaminhamentos, inclusive a judicialização dos conflitos que geraram a procura.

As demandas impostas compreendem a maior parte das que chegam ao assistente social e, sendo provenientes da determinação judicial, estão diretamente condicionadas aos motivos que levaram o juiz a solicitar o conhecimento técnico do assistente social, que deverá opinar a respeito de:

- permanência dos filhos com uma das partes nos casos em que estas não conseguem chegar a um consenso quanto à guarda e regulamentação de visitas; 
- pedidos de destituição de poder familiar, guarda, tutela, curatela, emancipação e regulamentação de visitas;

- medidas socioeducativas impostas aos adolescentes em conflito com a lei;

- concessão dos benefícios de saídas temporárias e/ou trabalho externo, livramento condicional para condenados no regime progressivo da pena;

- medidas de segurança impostas aos portadores de transtorno mental que cometeram delitos;

- penas e medidas alternativas impostas aos sentenciados que cometeram delitos suscetíveis a até quatro anos de detenção;

- restrição imposta pelo juiz no processo conciliatório de casais, parentes, vizinhos envolvidos em situações de violência interpessoal ou doméstica;

- condições impostas aos usuários de drogas no âmbito da vara de entorpecentes e contravenções penais.

Portanto, nem todos os conflitos que chegam às varas $e$ juizados são encaminhados ao assistente social, mas apenas aqueles que os magistrados, na maioria das vezes por meio de critérios subjetivos e morais, identificam como pertencentes ao âmbito de atuação do "profissional do Social".

Tem-se, de um lado, um ente jurídico representado na figura do magistrado, que atende a uma demanda institucional de resolução de conflitos judicializados e tem poder de decisão e, de outro, um ente não-jurídico representado na figura do assistente social, que atende à demanda institucional de "auxiliar" na resolução dos conflitos e que atua para garantir o acesso aos direitos dos sujeitos judicializados, mas o seu poder restringe-se à sugestão. 
A condição de ente não-jurídico atribuída ao assistente social permite, do ponto de vista institucional, a sua identificação como "profissional do Social", de forma que o campo de estudo, análise, avaliação e intervenção do assistente social não está, na sua essência, nem no jurídico, nem no psicológico e nem no pedagógico. O seu reconhecimento enquanto "profissional do social" perpassa a compreensão e explicação das "questões sociais" ou "problemas sociais" que tangenciam o campo jurídico-legal e psicológico.

Esse tangenciamento exige que 0 assistente social não apenas conheça a complexa e rebuscada linguagem jurídica, mas que traduza as letras da lei numa linguagem acessível e compreensível aos olhos dos usuários. Esse é um ponto importante por mostrar que, ao se tornarem objeto de trabalho não específico, mas privilegiado do assistente social no judiciário, aquelas demandas podem traduzir-se como expressões da questão social que interferem (ou podem interferir) na resolução do conflito judicializado. Dentre essas expressões da questão social, podemos citar: conflitos familiares ou intrafamiliares, alcoolismo, dependência química, desemprego, subemprego, analfabetismo, doença mental, violências, pobreza material e política, falta de informação, inacessibilidade a bens e serviços sociais, dentre outros.

Caracterizar o objeto de trabalho do assistente social como "privilegiado" significa dizer que, primeiro, as expressões da questão social não constituem, por excelência, o objeto de trabalho exclusivo do assistente social; e, segundo, que, apesar de seu conhecimento não ser, em essência, nem jurídico e nem psicológico, não significa que esse profissional esteja inabilitado ou não disponha de competência técnica para estabelecer as mediações necessárias na identificação, atendimento e encaminhamento das manifestações jurídicas e psicológicas imbricadas nas expressões da questão social. Por outro lado, ser o "profissional do Social", acaba por restringir, 
em certa medida, a sua atuação pela via única da assistência social e, com isso, impõe-se um limite à possibilidade de o assistente social ter reconhecidas a amplitude do seu campo de intervenção e a natureza interdisciplinar inerente ao Serviço Social.

Ao realizar as mediações entre as manifestações jurídicas e psicológicas imbricadas nas expressões da questão social, o assistente social dispõe de um conjunto de meios e instrumentos de trabalho - por exemplo: atendimento individual e familiar, visitas domiciliares e institucionais, abordagem multidisciplinar, redes sociais, pesquisa, projetos, programas, qualificação - necessários para dar materialidade institucional à profissão e à intervenção profissional, principalmente por meio da elaboração de relatórios e pareceres. Como o trabalho do assistente social pressupõe um fluxo crescente de entrada e saída de processos judiciais, a intensidade e a abrangência do uso dos meios e instrumentos de trabalho estão circunscritas ao tempo exigido para a realização do parecer ou relatório social, e são determinadas pelo nível de assessoramento do assistente social, ou seja, se esse assessoramento ocorre na imposição, execução e/ou no acompanhamento da "medida judicial".

A condição de "assessor" determina, também, o vínculo temporal e profissional do assistente social com o sujeito judicializado. O vínculo do usuário com a instituição - e, conseqüentemente, com o assistente social - está condicionado por dois fatores: primeiramente, o tempo necessário para a resolução do conflito, ou seja, o cumprimento da medida judicial imposta; e, em segundo lugar, o vínculo direto do usuário com o assistente social passa a ser mediado pela "compulsoriedade", já que a judicialização dos conflitos pressupõe a tutela dos sujeitos em conflito, diferentemente de outros espaços ocupacionais do assistente social onde o vínculo é mediado por uma relação de espontaneidade. 
Concretamente, se, por um lado, o assistente social é desafiado a, contraditoriamente, defrontar-se com aspectos jurídico-legais e ético-profissionais relacionados ao que a lei limita e proíbe e ao que a ética orienta e permite em termos de projeto profissional e societário, por outro lado, o vínculo que o assistente social estabelece com o sujeito em conflito com a lei extrapola, muitas vezes, o âmbito legal e institucional e, até mesmo, a vontade do usuário de se desvincular da "justiça".

Logo, pensar concretamente a resolução do conflito implica ter a perspectiva profissional de que o usuário possa reelaborar, reinterpretar e ressignificar as expressões da questão social que estão produzindo e reproduzindo conflitos nas suas relações sociais e que, muitas vezes, contribuem (ou estão contribuindo) para mantê-lo sob a tutela da justiça. No entanto, essa perspectiva depende do vínculo temporal estabelecido com o usuário, principalmente nos casos em que o assistente social subsidia o magistrado no acompanhamento da sanção judicial imposta ao sujeito judicializado, já que o tempo profissional do vínculo está subordinado ao tempo legal de cumprimento da "medida" judicial, principalmente nos conflitos de natureza criminal.

Por outra via, mesmo não sendo parte da instituição - apesar de se vincularem a ela até o término da resolução do conflito -, os usuários exercem uma influência indireta no reconhecimento e legitimação do trabalho do assistente social, sem contar que, neste caso, o reconhecimento é geralmente direcionado da instituição para o setor ${ }^{10}$ ao qual o profissional está subordinado e não diretamente a este.

10 Regimentalmente, dentro da divisão sociotécnica do trabalho do TJDFT, os profissionais que assessoram os magistrados das varas de família, da infância e adolescência, criminais, de execuções criminais e dos juizados especiais criminais estão inseridos em setores psicossociais, que são compostos por assistentes sociais, psicólogos e pedagogos. 


\section{O assistente social entre a "restrição de direitos" e a "garantia de direitos"}

A relação entre demanda institucional e demanda profissional revela que o trabalho do assistente social no judiciário apresenta um caráter simultaneamente mediador e contraditório, pois a mediação entre os preceitos e normas legais e os preceitos psicológicos e sociais é feita ao sugerir procedimentos e encaminhamentos que facilitam o acesso dos judicializados aos bens e serviços sociais disponíveis e, assim, garante a resolução dos conflitos no âmbito judicial. Por conseguinte, ao realizar essa mediação, o assistente social, contraditoriamente, atende tanto aos objetivos da instituição judiciária quanto aos objetivos profissionais.

Revela-se, então, que a lógica que justifica as determinações do trabalho do assistente social está nas condições socioinstitucionais e técnico-profissionais necessárias para que os magistrados estejam "aptos" a decidir sobre uma "medida judicial" e, conseqüentemente, a proceder à sua execução, acompanhamento e extinção. Ou seja, enquanto o poder institucional do saber jurídico aponta para o discurso legal da imposição, execução e acompanhamento da "medida judicial", o que implica "tutela", "fiscalização" e "policiamento", o saber profissional do assistente social aponta para o discurso da imposição, execução e acompanhamento, mas numa perspectiva de consolidação, garantia e ampliação de direitos, o que implica acolhimento e escuta profissional.

É a partir dessa perspectiva, orientada pelos princípios ético-profissionais, que o assistente social do judiciário tem assumido uma postura tanto de "ouvidor" - por informar, orientar e encaminhar os seus usuários para que se beneficiem dos recursos intra e extra-institucionais e das políticas e serviços sociais existentes -, quanto de "fiscalizador" - por denunciar, 
provocar e cobrar dos órgãos do poder executivo os direitos dos seus usuários no acesso a bens e serviços garantidos legalmente. Paradoxalmente - e considerando o caráter residual e paliativo das políticas sociais brasileiras pautadas em critérios seletivos e excludentes - o fato de estar tutelado pelo Judiciário apresenta-se, muitas vezes, como condição para que o usuário tenha acesso a bens e serviços que the seriam negados em outras esferas e circunstâncias, mas, agora, eles lhe são concedidos justamente pelo fato de esse Poder determinar que se faça desta ou daquela maneira.

É nesse espaço contraditório e mediador que o assistente social enfrenta um grande paradoxo: se, por um lado, a adequação dos conflitos (que, antes de serem jurídicos, são sociais) à esfera do direito normativo acaba despolitizando, individualizando e particularizando as expressões da questão social, cuja base encontra-se na conjuntura e estrutura sócio-histórica da sociedade brasileira, por outro lado, a utilização de seus conhecimentos e habilidades - tanto para se fazer conhecido e reconhecido perante a instituição e os profissionais das outras áreas do conhecimento, quanto para justificar e legitimar o seu espaço de atuação para além das protoformas da profissão - impõe-lhe limites e possibilidades que perpassam a construção da identidade, a autonomia e o reconhecimento profissional.

O fato de o seu trabalho condicionar o funcionamento da instituição (e estar condicionado por ela), torna-o dependente da burocracia e hierarquia excessivas, que, muitas vezes, dificultam a realização de suas atividades e retardam a aprovação e implementação dos projetos e programas propostos pelo assistente social. Também constituem obstáculos à sua atuação: a conjuntura político-financeira da instituição, a lentidão na reestruturação administrativa e na incorporação de princípios gerenciais ditos "modernos", como a informatização 
dos procedimentos judiciais e a descentralização das atividades judiciárias.

Esse condicionamento é reforçado, de forma direta, por vários fatores: mudanças político-administrativas que ocorrem a cada dois anos, resultantes de novas nomeações para a cúpula do Tribunal ou mesmo em função de aposentadoria, afastamento ou titularidade de magistrados; dependência dos magistrados, corregedoria e presidência na aprovação de projetos; falta de critérios formais e objetivos para a seleção dos cargos de direção dos setores; escassez de profissionais, espaço e infra-estrutura; e, falta de consultoria permanente na área de Serviço Social, que impossibilita a constante capacitação e qualificação profissional.

A produtividade que a instituição exige do assistente social está refletida nos relatórios e instrumentais estatísticos, sendo medida pela quantidade de atendimentos individuais, acompanhamentos e encaminhamentos, visitas domiciliares e institucionais, reuniões internas e externas, participação em encontros, seminários, contatos telefônicos e, principalmente, relatórios e pareceres sociais. Assim, pode-se observar que as exigências de rapidez e agilidade nos procedimentos técnicoprocessuais das varas e juizados interferem nos procedimentos e rotinas do trabalho do assistente social, principalmente no que se refere à determinação de prazos para a realização dos pareceres e relatórios, o que acaba prejudicando a qualidade do trabalho, já que o tempo exigido pelo magistrado para a realização do estudo social confronta-se com a exigência do uso de procedimentos técnico-profissionais e outras circunstâncias, muitas vezes, externas à instituição e alheias à competência do assistente social.

A autonomia do assistente social depende das varas ou juizados aos quais está subordinado, das necessidades 
e dos objetivos da instituição, e também da trajetória do profissional e dos seus pressupostos teorico-metodológicos e ético-políticos. Por um lado, o assistente social necessita ter competência profissional para "traduzir" e "redimensionar", perante os profissionais de outras áreas do conhecimento, as atribuições que, regimentalmente, Ihe competem, e, por outro lado, "traduzir" e "redimensionar" essas mesmas atribuições de acordo com as necessidades e objetivos da instituição nas diferentes conjunturas político-administrativas.

O maior grau de autonomia se expressa na sua capacidade de argumentação na definição das "frentes de trabalho", na utilização dos meios e instrumentos necessários para garantir o atendimento e o acompanhamento dos usuários, e na elaboração e avaliação dos planos, projetos e programas desenvolvidos. Já o menor grau de autonomia se expressa na definição das prioridades e na implementação dos projetos e programas que dependem da aprovação das instâncias superiores (juízes, corregedor e presidência) e, também, da conjuntura político-administrativa e político-financeira.

\section{Considerações finais}

Os paradoxos legais, jurídicos e institucionais que perpassam o trabalho do assistente social no Judiciário permitem levantar questões iminentes aos profissionais que recentemente têm caracterizado esse espaço profissional como Serviço Social Sociojurídico, pressupondo, assim, um objeto, teoria e metodologia próprios do Serviço Social nesse espaço ocupacional. Como pensar a problematização teóricometodológica que permeia o Serviço Social na sua interface com o Direito, a Psicologia e a Pedagogia? Como relacionar os preceitos legais, jurídicos e organizacionais do poder judiciário 
com os preceitos profissionais do assistente social? Como resgatar cotidianamente as mediações dos aspectos jurídicos e psicológicos que se entrecruzam com as expressões da questão social? Como analisar, teórica e metodologicamente, as particularidades do assistente social na utilização dos meios e instrumentos de trabalho compartilhados pelos profissionais da Psicologia e Pedagogia? Como pensar na efetivação dos princípios éticos que norteiam a profissão no contexto impositivo, fiscalizador e policialesco do Judiciário?

De um ângulo indicativo (mas não conclusivo), pode-se dizer que as determinações que dão orientação e direcionalidade ao ser e ao fazer profissional do assistente social no Judiciário apontam, constantemente, para desafios e possibilidades de buscar nos pressupostos teórico-metodológicos, técnicooperativos e ético-políticos da profissão as suas particularidades no processo de reprodução da vida social.

\section{Referências}

BARBOSA, J. C. O que é Justiça. São Paulo: Abril Cultural, 1997.

BOTTOMORE, T. Dicionário do pensamento marxista. Rio de Janeiro: Jorge Zahar, 1983.

CASTRO, F. A. V de. O Poder Judiciário na virada do século: paradigmas de atuação. Rio de Janeiro: Lúmen Júris, 1998.

COSTA, G. M. Serviço Social e a categoria trabalho. Recife, 1999. Dissertação (Mestrado em Serviço Social) - Universidade Federal de Pernambuco.

FARIA, J. E. Direito e justiça: a função social do Judiciário. São Paulo: Ática, 1989.

O Poder Judiciário no Brasil: paradoxos, desafios e alternativas. Brasília: Conselho de Justiça Federal, Centro de Estudos Jurídicos, 1996. (Série Monografias do CEJ, v. 3). 
HOLANDA, M. N. A. B de. O trabalho em sentido ontológico para Marx e Lukács: algumas considerações sobre trabalho e serviço social. Serviço Social e Sociedade, v. 23, n. 69, mar. 2002.

IAMAMOTO, M. V. Relações sociais e Serviço Social no Brasil: esboço de uma interpretação histórico-metodológica. 14. ed. São Paulo: Cortez, 2001.

O Serviço Social na contemporaneidade: trabalho e formação profissional. 4. ed. Cortez, São Paulo, 2001.

JUNQUEIRA, A. A Constituição democrática brasileira e o Poder Judiciário. [S.I.]: Centro de Estudos Konrad-Adenauer Stiftung, 1999. (Caderno Debates, n. 20).

LISBOA, G. A. Organização judiciária. Porto Alegre: Síntese, 1999.

MARX, K. O Capital. São Paulo: Nova Cultura, 1989. v. I, parte 3a, cap. V.

. Introdução à crítica da economia política. São Paulo: Abril Cultural, 1974.

A ideologia alemã. Lisboa: Presença, Martins Fontes, 1980. $2 \mathrm{v}$.

NETTO, J. P. Cinco notas a propósito da "questão social". Temporalis, Brasília, v. 2, n. 3, jan./jun. 2001.

OLIVEIRA JUNIOR, J. A. de O. Poder Judiciário e democracia. In: JUNQUEIRA, A. Constituição democrática brasileira e o Poder Judiciário. [S.I.]: Centro de Estudos Konrad-Adenauer Stiftung, 1999. (Caderno Debates, n. 20).

PEREIRA, Potyara A. P. A metamorfose da questão social e a reestruturação das políticas sociais. In: CURSO de Capacitação em Serviço Social e Política Social, módulo 3. Brasília: CEAD, 1999.

. Questão Social, Serviço Social e direitos de cidadania. Temporalis, Brasília, v. 2, n. 3, jan./jun. 2001.

. Relação entre Serviço Social e Assistência Social. Série Política Social em Debate, NEPPOS/CEAM/UnB, Brasília, v. 14, n. 7, jan./jun. 2001.

PONTES, R. N. Mediação e Serviço Social: um estudo preliminar sobre a categoria teórica e sua apropriação pelo Serviço Social. Campinas (SP): Cortez, Unama, 1995. 
SOUZA, M. F de. Condições, determinações e particularidades do processo de trabalho do assistente social nos órgãos do poder judiciário sediados em Brasília. Brasília, 2004. Dissertação (Mestrado em Política Social) - Universidade de Brasília.

TELLES, V. S. Sociedade civil e a construção de espaços públicos. In: DAGNINO, Eveline (Org.). Anos 90: política e sociedade no Brasil. São Paulo: Brasiliense, 1994.

YASBECK, M. C. Pobreza e exclusão social: expressões da questão social no Brasil. Temporalis, Brasília, v. 2, n. 3, jan./jun. 2001. 